\title{
Two cases of incidental Podostroma cornu-damae poisoning
}

elSSN: 2383-4625

\author{
Hee Nyung Kim, Han Ho Do, Jun Seok Seo, Hee Young Kim \\ Department of Emergency Medicine, Dongguk University Ilsan Hospital, Goyang, Korea
}

Podostroma cornu-damae is a rare, deadly fungus. However, it can be easily mistaken for antler Ganoderma lucidum. In this case report, two patients made tea with the fungus and drank it over a 2-week period. Both patients presented with bicytopenia, and one patient had desquamation of the palms and soles. Both were treated with prophylactic antibiotics and granulocyte colony-stimulating factor. One patient was admitted to the intensive care unit and received a platelet transfusion. Both patients were discharged without complications. Podostroma cornudamae infections caused by intoxication were successfully treated using our treatment strategy, which consisted of prophylactic antibiotics, platelet transfusion, and granulocyte colony-stimulating factor. We believe this report can guide future treatment.

Keywords Alopecia; Desquamation; Mushroom; Pancytopenia; Podostroma cornu-damae

Wapsule
$\begin{aligned} & \text { What is already known } \\ & \text { Podostroma cornu-damae can be fatal, and it resembles Ganoderma lucidum } \\ & \text { and Cordyceps in their early stages. Due to its similarity accidental poisoning is } \\ & \text { increasing. }\end{aligned}$
What is new in the current study
Though Podostroma cornu-damae presents with neutropenia and typical find-
ings such as alopecia and desquamation, only careful history can diagnose
mushroom poisoning. Conservative treatment with granulocyte colony-stimu-
lating factor and prophylactic antibiotics can be useful.

Received: 25 March 2016

Revised: 12 June 2016

Accepted: 16 June 2016

Correspondence to: Han Ho Do Department of Emergency Medicine, Dongguk University Ilsan Hospital,

27 Dongguk-ro, Ilsandong-gu, Goyang 10326, Korea

E-mail:erdohh@naver.com

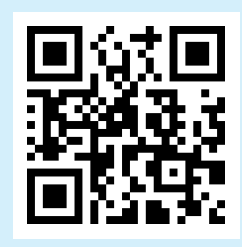

How to cite this article:

Kim HN, Do HH, Seo JS, Kim HY. Two cases of incidental Podostroma cornu-damae poisoning. Clin Exp Emerg Med 2016;3(3):186189.

This is an Open Access article distributed under the terms of the Creative Commons Attribution Non-Commercial License (http:// creativecommons.org/licenses/by-nc/4.0/). 


\section{INTRODUCTION}

Only approximately 30 of the thousands of mushrooms worldwide are known to be fatally poisonous. ${ }^{1}$ The most famous toxic mushroom is the genus Amanita, which contains the lethal toxin amatoxin. ${ }^{2}$ However, there are few reports regarding other mushroom species.

Podostroma cornu-damae is a lethal mushroom belonging to the Hypocreaceae family. It contains a lethal toxin called trichothecene mycotoxin. As this mushroom resembles antler Ganoderma lucidum and Cordyceps in the early stage, ${ }_{1}^{3}$ amateur mushroom hunters have mistaken Podostroma cornu-damae for these mushrooms. This has resulted in fatal accidents (Figs. 1, 2).

Many cases of accidental intoxication owing to this mushroom have been reported in Japan. In Korea, however, no cases were reported before 2013. Nevertheless, since then, cases of accidental intoxication of this mushroom have been reported. Here, we report two cases of poisoning by Podostroma cornu-damae.

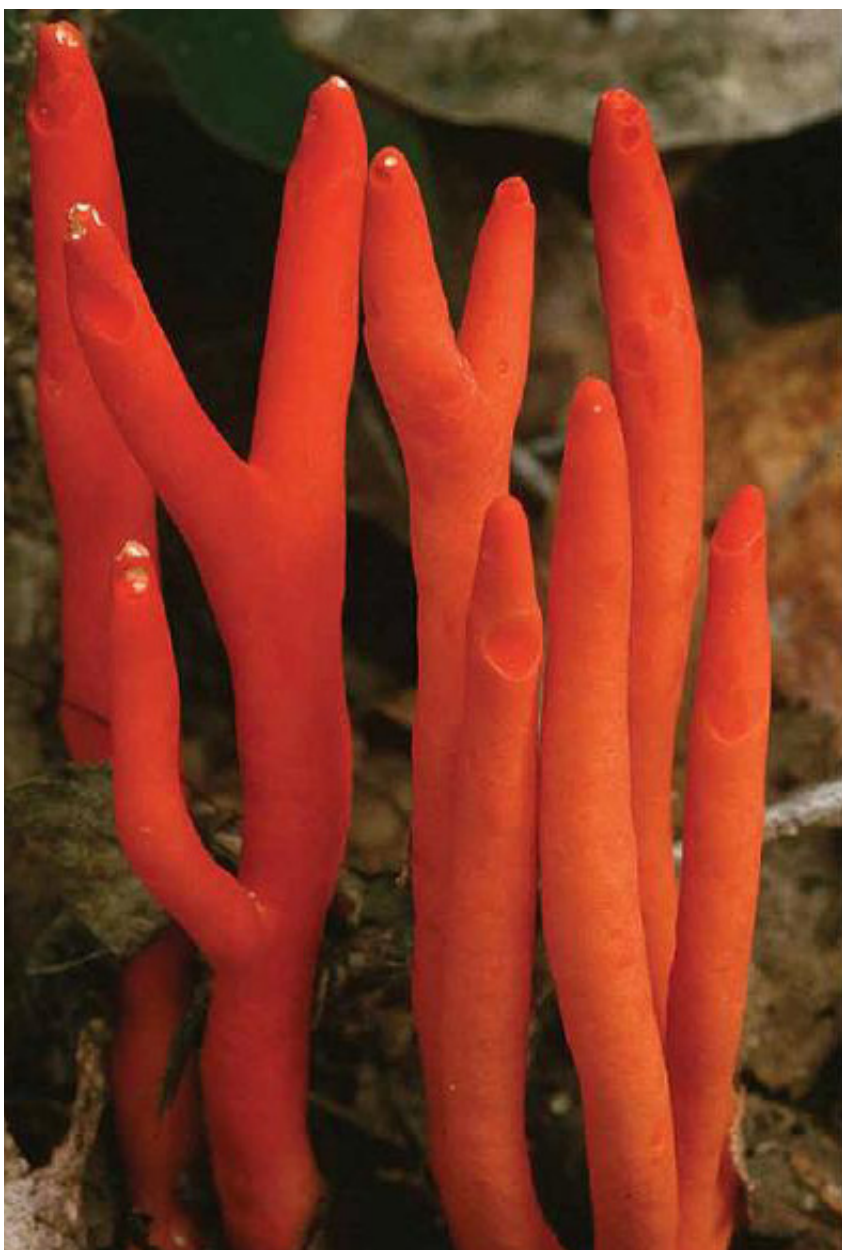

Fig. 1. Podostroma cornu-damae (Republished with credits to Taylor F. Lockwood, http://www.mushroom.pro).

\section{CASE REPORT}

\section{Case 1}

A 62-year-old woman, previously diagnosed with hypertension, was admitted to the emergency department due to desquamation of the hands and feet (Fig. 3) and alopecia (Fig. 4). The symptoms had started 7 days previously, and she tried taking oral medication and applying lotions prescribed by her dermatologist without improvement. The symptoms worsened, and she developed general weakness and mild nausea. Upon further questioning, she admitted that she had gathered wild mushrooms from a nearby mountain and had made tea from the mushrooms. She had been drinking 2 or 3 cups of mushroom tea for the previous 12 days.

On admission, her blood pressure was $115 / 64 \mathrm{mmHg}$, heart rate was 97 beats $/ \mathrm{min}$, and temperature was $37.7^{\circ} \mathrm{C}$. She complained of general weakness, fever, and light abdominal discomfort, and she had desquamation of the hands and feet and alopecia. There were no respiratory or gastrointestinal symptoms. Her

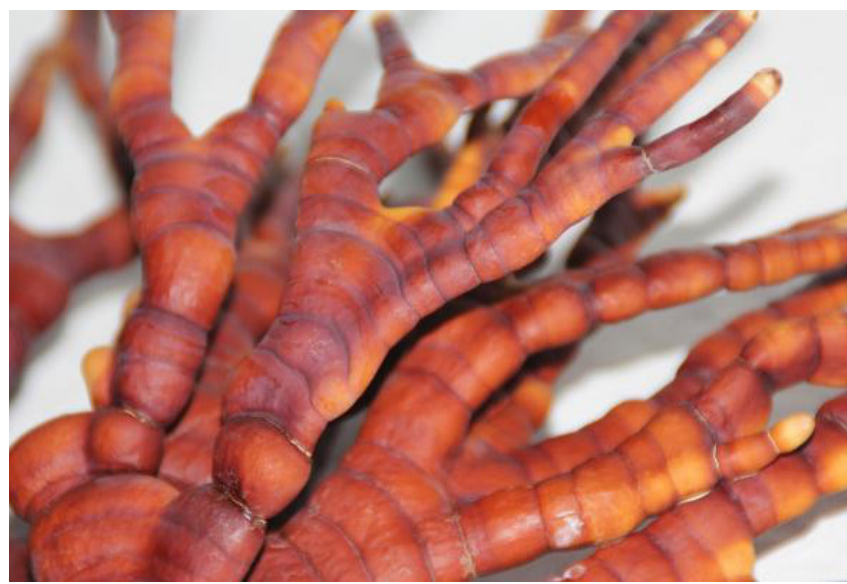

Fig. 2. Antler Ganoderma lucidum.

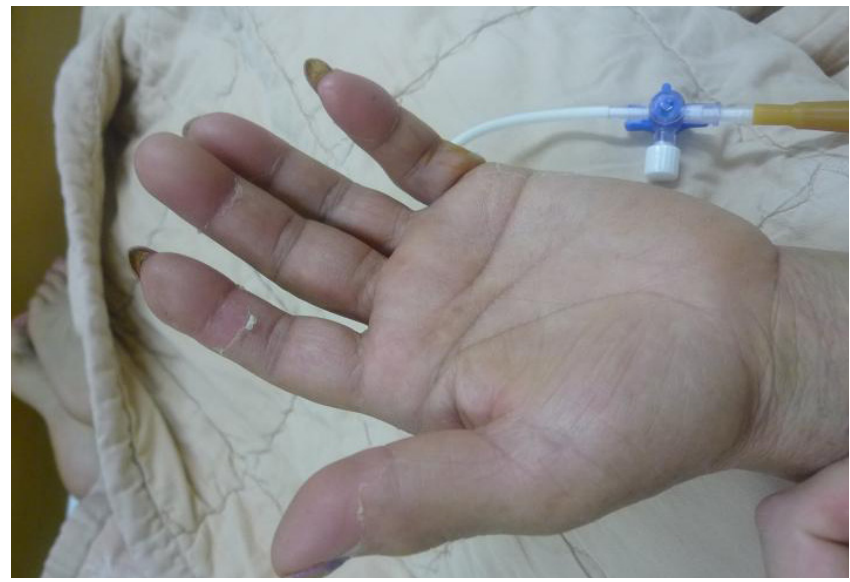

Fig. 3. Desquamation of the palms and fingers are present. 


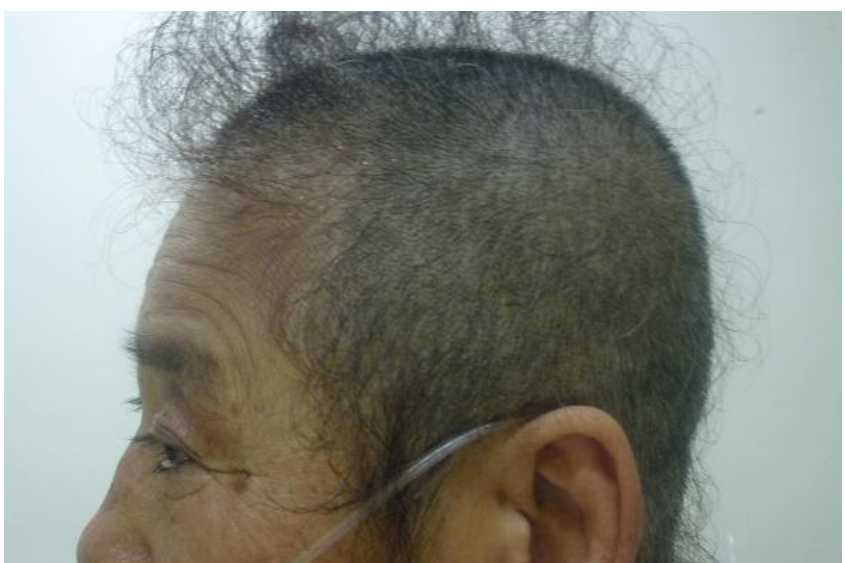

Fig. 4. Alopecia is evident.

physical examination showed no neurological deficits.

Blood tests showed severe bicytopenia with a white blood cell (WBC) count of $6,200 / \mu \mathrm{L}$ and an absolute neutrophil count $<10$, as well as a hemoglobin $(\mathrm{Hb})$ level of $11.5 \mathrm{~g} / \mathrm{dL}$ and platelet count of $29,000 / \mu \mathrm{L}$. Electrolyte panels and biochemical laboratory measurements were carried out. The patient's C-reactive protein (CRP) level was $21.18 \mathrm{mg} / \mathrm{dL}$, which was elevated above the normal range. Other test results were within normal limits (blood urea nitrogen $33.8 \mathrm{mg} / \mathrm{dL}$, creatinine $0.94 \mathrm{mg} / \mathrm{dL}$, aspartate aminotransferase $7 \mathrm{IU} / \mathrm{L}$, alanine aminotransferase $10 \mathrm{IU} / \mathrm{L}$, creatine kinase-MB $0.51 \mathrm{ng} / \mathrm{dL}$, and troponin T $0.019 \mathrm{ng} / \mathrm{dL}$ ). A peripheral blood smear showed severe neutropenia, while a chest radiograph and electrocardiograms showed normal findings.

Although her history suggested mushroom intake to be the cause of her abnormal laboratory measurements, she was admitted and treated with prophylactic antibiotics and granulocyte colony-stimulating factor (G-CSF). We tested for Hantaan virus, tsutsugamushi, leptospirosis, and malaria antibody to rule out other infections, and two sets of blood cultures were performed immediately. All of the results were negative. A bone marrow biopsy showed hypocellular bone marrow.

Neutropenia persisted during her hospitalization, and on the third hospital day, her platelet count decreased to $10,000 / \mu \mathrm{L}$. After 4 pints of platelet infusion and continuous G-CSF infusion, her blood cell count improved without any other infective, renal, or cardiovascular complications. On the thirteenth day of her hospitalization, the laboratory measurements showed a WBC count of $2,000 / \mu \mathrm{L}$, absolute neutrophil count (ANC) of 710 , segmented neutrophil count of $42 \%$, Hb level of $7.9 \mathrm{~g} / \mathrm{dL}$, and platelet count of $144,000 / \mu \mathrm{L}$. She was then discharged. One week later, at an outpatient follow-up visit, her blood cell count had recovered fully.

\section{Case 2}

The patient was a 62-year-old man and the husband of case 1 . He did not have gastrointestinal or cardiovascular symptoms, alopecia, or desquamation. However, he admitted to having drunk mushroom tea with case 1 . On admission, his blood pressure was $133 / 66 \mathrm{mmHg}$, heart rate was 66 beats/min, and body temperature was $37.5^{\circ} \mathrm{C}$. He was alert with no abnormalities upon physical examination. Initial laboratory results showed a WBC count of $1.75 \times 10^{3} / \mu \mathrm{L}$, ANC of 820 , Hb level of $14.3 \mathrm{~g} / \mathrm{dL}$, platelet count of $12 \times 10^{3} / \mu \mathrm{L}$, CRP level of $2.05 \mathrm{mg} / \mathrm{dL}$, blood urea nitrogen level of $15.0 \mathrm{mg} / \mathrm{dL}$, creatinine level of $0.99 \mathrm{mg} / \mathrm{dL}$, aspartate aminotransferase level of $18 \mathrm{U} / \mathrm{L}$, alanine aminotransferase level of $19 \mathrm{IU} / \mathrm{L}$, and procalcitonin level of $0.07 \mathrm{ng} / \mathrm{dL}$. He was admitted and treated with prophylactic antibiotics and G-CSF. On the fourth day of his admission, his neutropenia was aggravated, without fever. His ANC fell to < 10, and his CRP level was $13.33 \mathrm{mg} / \mathrm{dL}$. Under suspicion of concealed infection, prophylactic vancomycin was administered. This treatment was discontinued after cultures showed no growth. His antibody tests and cultures all yielded negative results (similar to case 1). On the twelfth day of his admission, his bicytopenia started to improve. On the eighteenth day of his admission, his complete blood cell count normalized, with a WBC count of $7,380 / \mu \mathrm{L}$, Hb level of $11.0 \mathrm{~g} / \mathrm{dL}$, and platelet count of 30,000 . He was subsequently discharged.

\section{DISCUSSION}

Podostroma cornu-damae is an ascomycete fungus and was originally described by Patouillard as Hypocrea cornu-damae (1895) and said to originate in Tibet. Podostroma cornu-damae was next described by Boedijn et al. (1934) and Doi et al. (1973). It was then published in Saccardo's famous Sylloge Fungorum (1905) and was named since. ${ }^{4}$ Many accidental poisonings by Podostroma cornu-damae can be attributed to its similarity to antler Ganoderma lucidum and Cordyceps (Figs. 1, 2). Podostroma cornu-damae is known to inhabit the Java Islands, Korea, Japan, and China. ${ }^{5,6}$

In 1999, five people in Japan drank sake made from about $1 \mathrm{~g}$ of this toxic mushroom, resulting in a death 2 days later despite intensive treatment. ${ }^{5}$ Another Japanese report documented 13 cases of ingestion, including 2 people who died. ${ }^{3}$ In Korea, 4 people have reportedly been intoxicated by this mushroom, of whom 3 drank tea made from its fruit body. One died of multi-organ failure, ${ }^{7}$ and the 2 others were discharged from the hospital without complications. ${ }^{7,8}$ One man was reported to have boiled the mushroom and eaten it. He developed nausea, vomiting, and fever within 3 hours of consumption. His lungs showed hemorrha- 
gic and necrotic changes, and he died within 12 days due to multiorgan failure. ${ }^{9}$

The case reported by Ahn et al., is similar to ours in many ways. The patient consumed the mushroom in tea form and showed similar symptoms such as fever, generalized weakness, alopecia, and desquamation of the palms and soles (as in case 1). Both were treated with prophylactic antibiotics, G-CSF, and platelet transfusion. Our patient recovered gradually, while the patient described by Ahn et al., ${ }^{7}$ despite being intubated and treated with continuous renal replacement, experienced worsening bilateral lower lung field consolidation and died due to multi-organ failure.

The most common complaints were abdominal pain, desquamation of the hands and feet, alopecia, perception changes, and speech impediment. Further evaluation showed blood cell count anomalies, such as pancytopenia or bicytopenia, and cerebellar atrophy. Autopsies showed that the patients died of multi-organ failure, including disseminated intravascular coagulation, kidney failure, and hepatic failure. ${ }^{10}$ These symptoms were similar to animals dosed with trichothecene mycotoxin. In Japan, researchers have identified macrocyclic trichothecene toxins, such as satratoxin $H$, satratoxin $H$ 12', 13'-diacetate, satratoxin H 12'-acetate, and satratoxin $\mathrm{H} 13^{\prime}$-acetate. The mice died the next day after they were injected with $0.5 \mathrm{~g}$ of the toxin. ${ }^{5}$

No specific treatment has been found for poisoning with this lethal mushroom, but one patient who showed severe hemophagocytosis and bicytopenia was treated with abundant intravenous fluids (12 liters over 9 hours), plasmapheresis, and G-CSF. He recovered fully after over 1 month of intensive treatment. ${ }^{6}$ Other patients, like ours, were treated using G-CSF and prophylactic antibiotics and recovered without complications.

The onset of symptoms depends on the amount and manner of oral intake. Cases in which a person drank or ate the fruit body itself resulted in intake of large amounts of the toxin, thereby leading to symptoms within only a few hours or few days. When patients make tea and drink small amounts of the mushroom over a long period, it takes 2 to 4 weeks for symptoms to appear.

In the current case, the patients complained of alopecia and desquamation of the hands, with no other symptoms. It took 2 weeks for these symptoms to develop. Both were treated with G$\mathrm{CSF}$, and their symptoms and abnormal laboratory measurements remitted without any complications. The mechanism by which alopecia and desquamation appears has not yet been discovered.

We hope these cases will help treat future patients who pres- ent with an unknown cause of neutropenic fever and pancytopenia as well as desquamation on their palms and soles. Furthermore, as the number of cases of Podostroma cornu-damae poisoning is increasing, physicians should be sure to ask patients about any history of ingesting wild mushrooms when such symptoms appear.

\section{CONFLICT OF INTEREST}

No potential conflict of interest relevant to this article was reported.

\section{REFERENCES}

1. Kim GW, Yoon SK, Jung YS, Choi SC. Clinical toxicology. 1st ed. Seoul: Koonja Medical; 2006.

2. Klein AS, Hart J, Brems JJ, Goldstein L, Lewin K, Busuttil RW. Amanita poisoning: treatment and the role of liver transplantation. Am J Med 1989;86:187-93.

3. Yokoyama K, Gonmori K. Increase of poisoning by tropical mushrooms in Japan in recent years. Chudoku Kenkyu 2009;22: 240-8.

4. Nelson SF. The most dangerous mushroom (that you've never heard of). Fungi 2011;4:4-6.

5. Saikawa $Y$, Okamoto $H$, Inui $T$, et al. Toxic principles of a poisonous mushroom Podostroma cornu-damae. Tetrahedron 2001;57:8277-81.

6. Suzuki $M$, Katoh $Y$, Kumagai $H$, et al. Successful treatment in a case of Podostroma cornu-damae poisoning, a deadly poisonous mushroom. Chudoku Kenkyu 2002;15:177-82.

7. Ahn JY, Seok SJ, Song JE, et al. Two cases of mushroom poisoning by Podostroma cornu-damae. Yonsei Med J 2013;54: 265-8.

8. Yu HM, Kim J, Kang S, et al. Mushroom poisoning by podostroma cornu-damae: a case report and review of the literature. $J$ Korean Soc Emerg Med 2013;24:469-72.

9. Jang J, Kim CH, Yoo JJ, et al. An elderly man with fatal respiratory failure after eating a poisonous mushroom podostroma cornu-damae. Tuberc Respir Dis (Seoul) 2013;75:264-8.

10. Koichi M, Haruo T, Toshihiro Y, Masami O, Sadao N, Koichiro K. Case report: food poisoning to death by Podostroma cornudamae, its case history and autopsy findings. Acta Criminol Med Leg 2003;69:14-20. 